\title{
Debate e Investigación El derecho andaluz del patrimonio histórico desde una perspectiva constitucional
}

Gerardo Ruiz-Rico Ruiz

Catedrático de Derecho Constitucional. Universidad de Jaén

\section{Resumen}

La creación del Estado de las Autonomías ha generado un proceso de descentralización y transferencia hacia las Comunidades Autónomas de las funciones públicas encargadas de la protección del Patrimonio histórico-artístico. El problema se ha planteado al no haberse regulado en la Constitución española de 1978 una división clara de las atribuciones que corresponden a las nuevas entidades territoriales y aquellas otras que se reservan para el Estado. Esta indeterminación está en el origen de algunos conflictos que han debido ser resueltos por la jurisprudencia constitucional. A partir de los pronunciamientos del Tribunal Constitucional se ha podido definir con mayor exactitud el contenido y alcance de las competencias estatuarias de las Comunidades, y en concreto también de la potestad legislativa de la Comunidad Autónoma de Andalucia en materia de bienes culturales.

\section{Palabras clave}

Patrimonio cultural

Legislación

Andalucia

Jurisprudencia constitucional

Competencias

\section{Referentes básicos para la protección jurídica del PH en el "Bloque de constitucionalidad". Andalucía}

La legislación aprobada en el Parlamento andaluz sobre Patrimonio Histórico dispone de un marco referencia que se ubica en el Capítulo tercero del Título Primero de la Constitución Española de 1978 (CE). Dentro de un contexto tan precario desde el punto de vista de las garantías jurídicas, el artículo 46 de la norma fundamental sitúa no obstante en la cúspide del ordenamiento una obligación de los poderes públicos destinada a la protección del patrimonio histórico, cultural y artístico.

Desde esta primera dimensión sustantiva, el principal problema para dar cumplimiento al objetivo señalado en el precepto en cuestión radica en la naturaleza esencialmente programática con que fue configurado por el constituyente ${ }^{1}$. A la dificultad antes mencionada, se debe añadir el escaso apoyo que brinda a su potencial virtualidad normativa una cláusula como la contenida del artículo 53$3^{\circ}$. La remisión que alli se hace a un desarrollo legislativo posterior del conjunto de los Principios Rectores de la política social y económica, evidencia de manera explícita la subordinación del mandamiento del artículo 46 a una esfera normativa infraconstitucional.

Por otra parte, la jurisprudencia constitucional no ha aportado hasta ahora criterios de interpretación suficientes como para determinar el grado de virtualidad normativa del principio rector proclamado en el artículo 46 de la CE. El hecho de que no haya sido utilizado en ninguna ocasión como canon de constitucionalidad para evaluar la legitimidad de normas inferiores en rango impide, en consecuencia, conocer la medida exacta de su eficacia como mandato vinculante para el conjunto de poderes públicos.

Pero con ello no se agotarían en su totalidad las cuestiones de índole constitucional que afectan a la protección del Patrimonio Histórico. Porque precisamente al atribuir a un legislador indeterminado la responsabilidad de concretar el significado y alcance de ese principio rector no se llegan a solucionar el problema que planteaba, también en esta materia, el complejo sistema competencial del Título VIII de la CE.

Esta otra dimensión constitucional del PH ha sido, por lo demás, la única que dispone de alguna referencia en la doctrina del TC, el cual se ha visto obligado a resolver algunos conflictos de naturaleza competencial entre Estado y Comunidades Autónomas (CCAA), deslindando de este modo las atribuciones constitucionales y estatutarias que cada uno ha asumido para cumplir con el objetivo previsto en el artículo 46 de la norma fundamental.

En este sentido, los parámetros constitucionales tampoco ayudan demasiado a la hora de definir los espacios competenciales. Los artículos 148 y 149 contienen referencias no muy concretas para determinar la frontera de la legislación estatal y de las autonómicas. 


\section{$064-065$ \\ Debate \\ e Investigación \\ El derecho andaluz del PH \\ desde una perspectiva \\ constitucional \\ PH48 - Abril 2004}

La impresión que se obtiene del examen de algunos de sus apartados es que no se ha seguido del todo la regla general que marca la dialéctica competencial bases/desarrollo normativo. Los elementos para concretar el contenido al que pueden aspirar las regulaciones aprobadas por los distintos poderes territoriales no parecen ser además de igual naturaleza. Así, para la ley autonómica, la CE parece emplear el criterio del "interés", como instrumento de medición del alcance de las posibles competencias que podrán asumir las CCAA sobre patrimonio monumental, artesanía, museos y bibliotecas (art. $148-1^{\circ}-15$ y $\left.16, C E\right)$. No obstante, en razón de la transitoriedad con que fueron diseñadas (véase el apartado segundo de ese mismo precepto), estas disposiciones constitucionales se han visto superadas durante el proceso autonómico. En el caso de las CCAA del 151 (junto a Navarra, Valencia y Canarias), a partir de una redefinición del campo material de la competencia autonómica, que omite en el Estatuto de Autonomía cualquier referencia al "interés" cultural estrictamente regional; para el resto (CCAA del 143), por una interpretación extensiva de las atribuciones estatuarias por el legislador de la Comunidad, a pesar de que éstas siguen estando limitadas formalmente por ese criterio de intervención.

De otro lado, la atribución principal que se menciona en el artículo 149, en cuanto competencia exclusiva del Estado, se centra únicamente en la defensa del patrimonio cultural, artístico y monumental español contra la exportación y la expoliación; junto a esta función tan específica, se añade una competencia que adopta un criterio dominical para otorgarle una segunda competencia sobre museos, bibliotecas y archivos, siempre y cuando éstos sean de titularidad estatal.

A la hora de determinar el alcance de las facultades asumidas por las diferentes instancias politico-territoriales en materia de Patrimonio Histórico es necesario tener en cuenta la función que puede desempeñar en esa operación el artículo $149-2^{\circ}$ de la norma fundamental. Se establece en esta cláusula una regla competencial en virtud de la cual el Estado va a considerar la cultura como un deber y atribución esencial, compatible no obstante con el ejercicio de las funciones que hayan sido atribuidas a las CCAA en esta misma materia ${ }^{2}$. El carácter concurrente de esta singular competencia anticipa ya la existencia de ámbitos materiales donde confluirán, en régimen de igualdad y dentro de una relación no jerarquizada, los ordenamientos estatal y autonómicos. Pero la principal aportación de esta cláusula constitucional resulta de la validación -como luego es posible comprobar en la jurisprudencia del Tribunal Constitucional- de una interpretación extensiva de las competencias del Estado sobre protección de bienes del Patrimonio Cultural $\left.\right|^{3}$. Lo que en todo caso parece poco probable es que esta norma cumpla sólo una función "residual" y con una esfera de proyección restringida ${ }^{4}$. Más bien al contrario, la generalidad con que ha sido formulada esa responsabilidad de los poderes públicos centrales sobre la "Cultura" admitiría en principio su utilización por éstos como un título habilitante "poliédrico" y multifuncional, del que no está excluida la materia competencial especifica sobre patrimonio histórico ${ }^{5}$. De hecho, así se ha puesto en evidencia de manera fehaciente con la publicación de una Ley general sobre Patrimonio histórico, artístico y cultural (Ley de 25 de Junio de 1985), cuyos contornos materiales sobrepasan con mucho la competencia estatal señalada en el artículo $149-1^{\circ}-28$, limitada a aspectos puntuales como la expoliación y exportación ilegal de los bienes de interés cultural.

Obviamente la responsabilidad del Estado en orden a garantizar ese "servicio de la cultura" no puede llevar a una invasión infundada de las potestades igualmente cedidas a las CCAA en virtud de sus respectivos Estatutos. En lo que respecta concretamente al Estatuto andaluz, y con carácter específico a la conservación del patrimonio cultural, se han establecido algunas que entran en juego en el ejercicio de modulación que va a necesitar la interpretación de las competencias estatales.

Por lo tanto, de la regulación constitucional es posible inferir a priori la existencia de ámbitos materiales considerablemente extensos para la actividad de los legisladores autonómicos. La única condición obviamente es que esas esferas objetivas, susceptibles de quedar enclavadas entre las atribuciones reservadas a las CCAA, hayan sido previstas en sus respectivos Estatutos de Autonomía. En el caso de Andalucia se han configurado dos categorias de títulos que afectan directamente a la conservación por parte de la Comunidad del patrimonio histórico. En calidad, primero, de competencias exclusivas de la Comunidad se reconocen tres responsabilidades básicas, orientadas a la promoción y fomento de la cultura en todas sus manifestaciones y expresiones (Art. 13-26), el patrimonio histórico, artístico, monumental arqueológico y científico y, por último, los archivos, museos y bibliotecas de titularidad no-estatal (art. 13-27\%). En segundo lugar, el Estatuto ha reservado asimismo a la Administración autonómica una competencia "ejecutiva" (De la legislación estatal) enfocada especialmente a museos, archivos, bibliotecas y otras colecciones de naturaleza análoga de titularidad estatal (art.13-8º.

Pero además, y de forma particular en la Comunidad de Andalucía, el Estatuto otorga también a la protección del patrimonio histórico-artístico la condición de compromiso fundacional u objetivo básico de la Comunidad Autónoma (art. 12-3-6, EAA). Ciertamente por ello, y a pesar del grado de indeterminación con que ha sido consagrada esta versión estatuaria del principio rector constitucionalizado en el artículo 46, cabe extraer un "plus" de eficacia a nivel autonómico del deber de conservación que recae sobre los bienes culturales, tal y como sucedería con el conjunto de fines consagrados en el artículo 12 del Estatuto andaluz ${ }^{6}$.

De la regulación contenida en la norma fundacional de la Comunidad Autónoma se infiere netamente la utilización de un doble criterio a la hora de componer las atribuciones culturales de aquélla. De un lado, el elemento de la titularidad parece representar un factor de delimitación competencial en la materia referida a museos, archivos y bibliotecas; en tanto que para la intervención pública autonómica sobre la mayoría del patrimonio histórico-cultural no parece haber quedado definido un principio claro ni rotundo. Efectivamente, el propósito básico apuntado por el artículo 12 se orienta hacia una protección centrada exclusivamente en los bienes culturales "de An- 
dalucia"; de esta manera se estaría implantando, indirectamente, la teoria del "interés", como instrumento con el que llevar a cabo en esta materia una operación de deslinde competencial. Sin embargo, la potestad que se ha atribuido concretamente a Andalucia ha quedado definida por el artículo 13-27 ${ }^{\circ}$, lo que implica una extensión del título competencial más allá de lo que se entienda por patrimonio histórico-artístico de "interés autonómico", esto es, con una relevancia cultural no estatal. Sin duda, la segunda alternativa resulta más correcta a los fines indicados en la CE y el propio Estatuto, ya que no se debería utilizar como parámetro jurídico un canon -el del interés sólo o predominantemente autonómico- que resulta imposible fijar desde un punto de vista "cultural" strictu sensu.

En todo caso, la Ley estatal sobre Patrimonio Histórico (Ley 16/1985, LPHE), primero, y la doctrina del Tribunal Constitucional más tarde, han marcado las principales líneas de una frontera ambiguamente trazada entre las competencias estatales y autonómicas.

\section{La doctrina del Tribunal Constitucional sobre PH}

La línea argumental de la jurisprudencia constitucional parte de la consideración elemental del carácter concurrente de la materia "cultura", sobre la cual -afirma ya en la Sentencia 84/1985- es imposible "establecer ámbitos competenciales excluyentes" entre Estado y CCAA. Desde este planteamiento inicial, se ha querido también puntualizar el sentido del artículo $149-2^{\circ}$ de la CE, y su proyección sobre las atribuciones "culturales" estatutarias de las CCAA. De este modo, el Tribunal ha remarcado la idea de que el Estado está legitimado para llevar a cabo una acción preferente en orden a "la preservación del patrimonio cultural común", así como todo para "aquello que precise de tratamientos generales o que hagan menester esa acción pública cuando los bienes culturales pudieran no lograrse de otras instancias" (STC 49/1984).

La norma fundamental estaría por tanto garantizando implícitamente al Estado una posición legislativa y administrativa "subsidiaria", cuyo alcance real se estableceria en base a consideraciones de oportunidad difícilmente fiscalizables desde un punto de vista jurídico-constitucional. A partir de esa interpretación, tanto el legislador nacional como la Administración central encargada de la custodia y conservación del patrimonio cultural se encuentran habilitados perfectamente para decidir cualquier medida que, por razones de uniformidad o de eficacia, sea necesarias necesaria para proteger los distintos bienes que componen el Patrimonio cultural. Desde la interpretación que sustenta el TC, no sería el tipo o categoría del "interés cultural" del bien lo que puede justificar la actuación prioritaria del Estado; la clave que determina la división de competencia se encuentra, por el contrario, bien en la conveniencia de establecer una regulación normativa de ámbito estatal, bien en la pasividad o inoperatividad de la intervención administrativa autonómica. Esta construcción jurispru- dencial sobre una subsidiariedad cultural es mucho más favorable a un proceso de centralización de los títulos competenciales en la materia que la teoría de un "interés respectivo", en la medida en que, mediante aquélla, va a resultar siempre más compleja la evaluación de potenciales invasiones sobre las competencias de las CCAA.

En todo caso, la indefinición constitucional ha contribuido a la generación de algunos conflictos en donde ya no era sólo el principio del "interés" el origen de la controversia entre dos poderes políticolegislativos con atribuciones en la defensa del PH. También se han producido colisiones de esta naturaleza al intentar una Comunidad Autónoma interpretar el contenido de uno de sus títulos competenciales en función del principio de "territorialidad". Sucedió precisamente con Andalucía con motivo del Recurso de inconstitucionalidad presentado por el Gobierno del Estado contra la Ley 3/1984 del Parlamento regional de Andalucía, de Archivos. El objeto de la impugnación recayó en aquellos preceptos de la norma andaluza que habian establecido como parte integrante del Patrimonio Documental de la Comunidad Autónoma todos los instrumentos documentales existentes y producidos por personas fisicas y jurídicas establecidas dentro del ámbito territorial de la Comunidad. Entre esa documentación había que incluir la documentación producida por gestores de servicios públicos, personas al servicio de cualquier órgano de carácter público, documentos producidos por los órganos periféricos de la Administración central o de cualquier otro órgano de titularidad estatal en Andalucia, así como de entidades eclesiásticas y Asociaciones o Sociedades radicadas en Andalucia.

En la argumentación que se recoge en el fallo (STC 103/1988) se observa ya la teoría con la que el Tribunal ha llevado a cabo una verdadera "recreación" de la competencia del Estado sobre PH. En efecto, si bien ese título aparecía limitado en su enunciado constitucional (art. 149-1 ${ }^{\circ}-28$ ) a lo que sería la regulación normativa contra determinadas actividades ilícitas contrarias a la conservación de los bienes de interés cultural (expoliación y exportación), la traducción que le otorga ahora la jurisprudencia constitucional se amplía a todos los posibles ámbitos del concepto de patrimonio histórico-artístico, incluido también el contenido en soportes documentales de archivos, y a cualquier función que contribuya a su conservación. El resultado de esta interpretación dilatada o, si se quiere "integral", de la competencia estatal va a tener una proyección inmediata sobre el alcance de los títulos competenciales de la Comunidad sobre PH (Art. 13$27^{\circ}$ y $28^{\circ}$, EAA); de tal forma que -en palabras del propio TC- "el ejercicio de la competencia exclusiva de la Comunidad Autónoma andaluza en materia de archivos (radicados o localizados en su ámbito territorial y de titularidad no estatal) debe adecuarse al límite mismo dimanante de la previsión del artículo 149-1-28 de la Constitución".

Pero otra de las cuestiones más problemáticas que debió resolver la Sentencia 103/1988 hacía referencia a la combinación de diferentes criterios de delimitación competencial (interés, titularidad, territorialidad). En este sentido el Tribunal destaca en primer lugar la diferencia que la Ley andaluza establece entre "documento" y "archivo", para aceptar la legitimidad de la Comunidad Autónoma 


\section{$066-067$ \\ Debate e Investigación}

El derecho andaluz del PH desde una perspectiva constitucional

\section{PH48 - Abril 2004}

a la hora de regular todo aquello que -englobado en el primero de esos términos- constituye el llamado "patrimonio documental andaluz". En definitiva, se acepta como componente de la competencia autonómica otorgada por el artículo $13-27^{\circ}$ del Estatuto andaluz la facultad de "definir el patrimonio documental de Andalucía, en cuanto parte integrante de su patrimonio histórico, así como para determinar los documentos radicados en su territorio que constituyen ese patrimonio".

Ahora bien, lo anterior no puede suponer -a juicio del TC- la aplicación del régimen jurídico establecido por la Comunidad para el Patrimonio documental andaluz a aquellos documentos y archivos de titularidad estatal ubicados en el territorio de la Comunidad; de lo contrario se estaría vulnerando el orden constitucional de competencias, que otorga al Estado una competencia exclusiva sobre archivos de su propia titularidad (Art. 149-1ํ-28, CE). En realidad, se trataba así de mantener la constitucionalidad de la ley andaluza mediante una "interpretación conforme a" Constitución, pues del enunciado de los preceptos impugnados se deducía claramente un ámbito de aplicación que no tenía en cuenta el criterio de la "titularidad".

Por último, la STC 103/1988 aporta un dato más que, sin embargo, no aclara demasiado -a nuestro entender- el significado de las cláusulas que componen el bloque de constitucionalidad, y en especial en lo relativo a la virtualidad que tiene en este punto el criterio del "interés". Nos referimos al alcance que puede llegar a tener el criterio de la "localización" del bien cultural objeto de protección. Precisamente con este elemento de valoración el TC desestima las alegaciones de inconstitucionalidad de la Ley de Archivos andaluza.

Por último, la STC 103/1988 aporta un dato más que, sin embargo, no aclara demasiado -a nuestro entender- el significado de las cláusulas que componen el bloque de constitucionalidad, y en especial en lo relativo a la virtualidad que tiene en este punto el criterio del "interés". Nos referimos al alcance que puede llegar a tener el criterio de la "localización" del bien cultural objeto de protección. Precisamente con este elemento de valoración el TC desestima las alegaciones de inconstitucionalidad de la Ley de Archivos andaluza.

La línea argumental de la Sentencia se detiene a comprobar que el Estatuto de Autonomía confería en su artículo $13-28^{\circ}$ a la Comunidad la competencia "en materia de archivos, museos, bibliotecas y demás colecciones de naturaleza análoga que no sean de titularidad estatal". Sobre la base de su ubicación en el territorio de la Comunidad Autónoma, la Jurisprudencia constitucional rechaza cualquier tesis de la que se pretende inferir un título competencial en favor del Estado "referido a archivos de titularidad no estatal que pertenezcan o se integren en entidades de ámbito territorial superior al de la Comunidad ni se especifica tampoco, como parece indicar la demanda, que la competencia de ésta se extienda sólo a archivos de interés para la Comunidad Autónoma" (Fundamento Jurídico 5). Esta resolución contribuye indirectamente a reinterpretar cualquier otra competencia "cultural" de las CCAA en una clave de "territorialidad" - ubicación del archivo dentro de la Comunidad- que permitiría ampliar sus límites funcionales en esta concreta materia. El criterio del "interés" pasa así a un segundo plano frente al anterior, el cual quedaría limitado únicamente por el de la posible "titularidad estatal" de los documentos o los soportes cultural/administrativos en los que se encuentren.

Pero con toda seguridad la doctrina más relevante para determinar los poderes normativos de la Comunidad Autónoma sobre patrimonio histórico-artístico se contiene en la STC 17/1991. Aunque la resolución trae causa de una impugnación donde no participa la Junta de Andalucía, las tesis que alli se exponen son de indudable aplicación para conocer el significado de las atribuciones estatuarias que se le han conferido al legislativo y la Administración cultural andaluces. El

\section{Voces}

\section{Por una implicación cualificada de los ciudadanos en la tutela de lo patrimonial}

\section{Ana Ávila > Ángela Espín}

Asociación de Profesores para la Difusión

y Protección del Patrimonio Ben Baso

La Asociación surgió con un doble objetivo: profundizar en el conocimiento del Patrimonio sevillano y contribuir, mediante la implicación ciudadana, a su protección. La defensa colectiva del Patrimonio a través de la difusión de su conocimiento es quizá el elemento identificador que define la actuación de Ben Baso dentro del mundo de las asociaciones vinculadas al $\mathrm{Pa}-$ trimonio. Esta línea de trabajo surge, lógicamente, del perfil docente de la mayor parte de sus miembros y, aunque la vertien- te sea de educación no formal, hay un planteamiento de objetivos y contenidos, y una definición de las estrategias y actuaciones que deben ser seguidas para alcanzarlos.

La sensibilidad ante las situaciones de abandono, la implicación colectiva en la conservación sólo puede ser fruto de una conciencia del valor del bien y del orgullo por su posesión, como puede observarse en la preservación de determinados monumentos o costumbres populares. Nuestra labor va en la linea de fomentar entre la ciudadanía el conocimiento del $\mathrm{Pa}$ trimonio, de ahi la importancia que damos a la difusión como medio de defensa del mismo. Las campañas de denuncia buscan siempre esta participación colectiva: envio de tarjetas a los organismos competentes, recogida de firmas, concursos fotográficos (véase la referencia a Patrimonio en Peligro, en la sección Noticias y Comentarios de este número), celebración de jornadas de puertas abiertas, organización de mesas redondas, presencia en los medios. 
recurso fue interpuesto por Cataluña, País Vasco y Galicia contra varios de los preceptos de la Ley estatal de 25 de Junio de 1985, reguladora del Patrimonio Histórico (Ley 16/1985). En su respuesta el Tribunal desestima totalmente la demanda, si bien en algún caso obliga a interpretar algunas de esas disposiciones legislativas conforme a una exégesis más adecuada al Bloque de constitucionalidad.

La Sentencia 17/1991 se encarga en primer lugar de destacar la necesidad de establecer un régimen jurídico unitario y estatal para aquellos bienes culturales que contengan un valor singular, considerados como "patrimonio cultural de todos los españoles e incluso de la comunidad internacional". En tanto que elementos de identificación de la cultura de un país, el Estado se encuentra perfectamente legitimado para intervenir en su conservación, con independencia de que ésta no haya sido una tarea otorgada de forma muy explícita por la Constitución a la Administración central.

Pero una contribución más significativa si cabe es la que se extrae de la "reconstrucción" que lleva a cabo aqui el TC de la competencia estatal prevista señalada en el artículo $149-1^{\circ}-28$, y en concreto del concepto alli utilizado de "expoliación". Ante las competencias autonómicas culturales, sancionadas en los Estatutos de Autonomía, el Tribunal acepta la interpretación que mantiene la Ley estatal del concepto genérico de "cultura" (149-2), en la cual a su vez se apoya la inclusión de categorías especificas de bienes culturales comprendidos en las definiciones -de configuración legal- de patrimonio histórico, artístico, monumental, arqueológico y científico. Partiendo de esta concepción amplia de la cultura, la jurisprudencia constitucional va a legitimar todas las atribuciones del Estado orientadas a la preservación de ese "patrimonio cultural común", así como cualquier tipo de "tratamientos generales" o acciones públicas necesarias para realizar "fines culturales que no pudieran lograrse desde instancias" (autonómicas). Por otra parte, las competencias estatales en materia de
Patrimonio se pueden considerar ampliadas de manera extraordinaria en virtud de la interpretación que hace el Tribunal del concepto de "expoliación" en la Sentencia 17/1991. La acepción constitucional de expoliación -afirma - "no debe quedar limitada al estricto significado gramatical del término", sino que "abarca un conjunto de medidas de defensa que a más de referirse a su deterioro o destrucción tratan de extenderse a la privación arbitraria o irracional del cumplimiento normal de aquello que constituye el propio fin del bien según su naturaleza"7. Desde este punto de vista, la competencia exclusiva que se otorga al Estado va a adquirir una dimensión potencial mucho mayor a la prevista inicialmente por el constituyente; a nuestro modo de ver, podría legitimar de hecho cualquier intervención -preventiva, sancionatoria o simplemente administrativa- de las autoridades estatales dirigida a la conservación de los bienes de interés cultural.

Está muy claro, por consiguiente, que se ha configurado una nueva competencia del Estado más allá de la dicción literal recogida en el artículo $149-1^{\circ}-2$, a partir de una exégesis que permite al Legislador estatal establecer "aquellos principios institucionales que reclaman una definición unitaria", o lo que es lo mismo, un estatuto jurídico general válido para todo el territorio nacional. Sin embargo, lo anterior no exime de una puntualización necesaria -que sugiere igualmente el Tribunal- al considerar que esta competencia estatal no puede dejar vacios de contenido los títulos que concurren en la materia y que confieren a las CCAA una competencia incuestionable en la conservación de patrimonio histórico y artístico que existe el ámbito territorial de cada una de ellas.

Uno de los contenidos esenciales de esa atribución autonómica queda delimitado por la potestad para declarar un bien de "interés cultural". Justamente ésta fue una de las claves que motivaron el recurso contra la Ley 16/1985, al establecer uno de sus preceptos (art.9) que esa operación básica en el procedimiento administrativo
Este planteamiento pedagógico es lo que nos justifica como "Asociación de Profesores". Al núcleo inicial de profesores de primaria, secundaria y de adultos se han ido incorporando de todas las especialidades y niveles, incluido el universitario. Por otra parte, las Jornadas de Difusión que la Asociación celebra todos los años han servido para que muchos ciudadanos nos conozcan y se identifiquen con nuestra línea de actuación, lo que nos ha llevado a ampliar la proporción de asociados no docentes hasta un treinta por ciento para dar cabida a personas que, desde el punto de profesional (arqueólogos, conservadores, estudiantes, etc.) o puramente personal, desean implicarse de forma activa en la defensa del $\mathrm{Pa}$ trimonio. La colaboración entre personas de distintas procedencias y profesiones ha permitido enriquecer las aportaciones y la formación de los miembros en un proceso participativo de aprendizaje y concienciación colectiva.

Nuestro concepto de Patrimonio se ha ido enriqueciendo, profundizando y ampliando a lo largo de estos años. Acercándo- nos, de hecho, a la definición y a los campos de actuación que define la UNESCO, hemos ido asumiendo que el patrimonio no es sólo el elemento monumental y artístico. La herencia cultural que debe preservarse para futuras generaciones es algo mucho más complejo, abarca otros muchos aspectos de la vida y la memoria, como el patrimonio natural, los modelos urbanos y rurales amenazados por la especulación y el tráfico, los espacios públicos y de encuentro, los valores de la tolerancia y la convivencia. La defensa de la paz.

La Asociación tiene, en este sentido, una vocación de defensa del patrimonio menos conocido y más frágil como es la arquitectura civil, la trama urbana tradicional, los yacimientos arqueológicos y la preservación de formas tradicionales de habitación, priorizando siempre el derecho a unas condiciones de vida dignas acordes con los tiempos. Consideramos clave el papel de la ciudadanía en la conservación del legado patrimonial, no desde posturas conservacionistas reaccionarias sino 


\section{$068-069$ \\ Debate e Investigación \\ El derecho andaluz del PH desde una perspectiva constitucional \\ PH48 - Abril 2004}

para la conservación del PH se llevaría a cabo mediante "Real Decreto", lo que significaba de hecho un potencial desapoderamiento de las facultades autonómicas previstas para ese mismo cometido. Pero la tesis sustentada por el TC permitiria salvar la posible tacha de inconstitucionalidad de la norma estatal siempre que se respetara la interpretación "conforme a Constitución" exigida en la sentencia. A su juicio, sólo cabía admitir una atribución estatal de esta naturaleza en los supuestos específicos contemplados en una de las disposiciones de la Ley (art. 6-b: bienes adscritos a servicios públicos gestionados por la Administración del Estado o que formen parte del Patrimonio Nacional). Sería por consiguiente contrario al orden de competencias del bloque de constitucionalidad privar a las CCAA de la competencia ejecutiva para emitir la declaración formal de interés cultural, decisión que resulta necesaria para llevar cabo una tutela específica de los bienes que componen del $\mathrm{PH}$.

Pese al intento de la jurisprudencia constitucional por concretar el significado de la competencia estatal enunciada por el artículo 149$1^{\circ}-28$, subsiste todavía una elevada dosis de indeterminación sobre el contenido que puede llegar a alcanzar el concepto básico - expoliación - en la que asienta esa atribución estatal. Como hemos podido comprobar, en su Sentencia 17/1991, el TC se aparta de una interpretación puramente gramatical, para otorgarle por el contrario una acepción finalista ${ }^{8}$. En efecto, a partir del fundamento que proporcionaría otro principio constitucional (la función social, art. 33-2 CE) a la intervención del Estado, se concibe la expoliación, como "la acción u omisión que ponga en peligro de pérdida o destrucción todos o algunos de los valores de los bienes que integran el Patrimonio Histórico Español o perturbe el cumplimento de la función social". Es evidente que con una acepción como ésta, es posible extender la competencia estatal hasta límites imprevistos por el constituyente. Pero al admitir una versión legislativa tan amplia e indefinidida de la noción de "expoliación", la jurisprudencia constitucional llega a la conclusión de que no cabe hacer reproches contra la Ley del $\mathrm{PH}$, sino en todo caso contra la aplicación que pueda hacer la Administración competente en cada caso concreto. Y aún más, significa igualmente la configuración de una especie de atribución "subsidiaria" del Estado, en la medida en que la intervención de éste va a quedar justificada en cualquier situación de riesgo, ya no sólo de "pérdida o destrucción" sino siempre que no se garantice el cumplimiento de esa función social a la que se adscribe forzosamente la utilización de los bienes culturales. Este planteamiento contribuye a fundamentar la legitimidad de las cláusulas de la Ley -a pesar de que resulten potencialmente lesivas de las competencias autonómicasdonde reside el fundamento constitucional de ese principio de subsidiariedad de la acción administrativa estatal en materia de cultura?.

La interpretación que se puede hacer, a su vez, de la exégesis propuesta por el TC conduce invariablemente a sostener la prioridad del contenido sustantivo de un mandato constitucional, como el contenido en el principio rector del artículo 46, CE, frente a la dimensión competencial de este último comprendida en el bloque de constitucionalidad (CE y EEAA). Esta posición prevalentemente "garantista" encuentra eco en alguna otra resolución de la jurisprudencia constitucional, en la cual se consiente -temporalmente al menos- la invasión de una competencia autonómica, para evitar perjuicios mayores en el cumplimiento de un objetivo/fin consagrado por la norma fundamental dentro también de la categoría de los principios del Capítulo tercero (medio ambiente) ${ }^{10}$. Ahora bien, precisamente esta otra referencia jurisprudencial permitiria mantener una tesis opuesta a la apropiación por el Estado de un espacio competencial que corresponde por derecho a las CCAA. La propia Ley de $\mathrm{PH}$ reconoce explícitamente que la actuación administrativa (contra la expoliación) debe corresponder prima facie al Departamento administrativo de la Comunidad Autónoma, por lo que la intervención ejecutiva del Estado resulta siempre sustitutiva de la de desde el hecho de reconocernos en nuestro pasado, vinculándolo al presente como forma de vida e integrándolo en un mundo de innovación.

Lo que en un principio se planteó como una acción de convertir las calles en aulas ha repercutido también en nuestra actividad docente, se ha producido un efecto retro-alimentador. La didáctica del Patrimonio se está enriqueciendo, el alumnado empieza a implicarse de forma activa, se sensibiliza ante las prácticas vandálicas, participa en las actividades y arrastra a amigos y familiares.

La participación de los ciudadanos en la defensa del Patrimonio ha de incidir en las politicas de protección, apoyándolas y exigiéndolas, aunque se creen, a veces, tensiones con las distintas administraciones, sobre todo y en los últimos tiempos por cuestiones relacionadas con nuevas construcciones en los cascos históricos y la sobreexplotación del suelo, lejos de lo marcado por las leyes de Patrimonio y por las cartas internacionales.

En suma, defendemos la implicación cualificada de los ciudadanos en las tareas de tutela de lo patrimonial más allá del campo profesional y político, desde posturas cívicas y éticas, que son voluntarias pero no voluntaristas y que nacen de la clara idea de la necesidad de la participación ciudadana y de la fuerza social del "tercer sector".

Ben Baso, en este sentido, no sólo mantiene convenios con otras asociaciones patrimoniales dentro de Sevilla, Andalucia, España y Europa sino también se coordina con otros grupos y plataformas ciudadanas en temas puntuales e incluso tutela el nacimiento de nuevas asociaciones. 
aquél. Pero además, aquella actuación administrativa de la entidad territorial (primaria versus a la subsidiaria de las autoridades estatales) puede y debe estar respaldada por una base normativa de rango legal y autonómico. Esto no significa que el Legislador central haya sido desprovisto de la capacidad para regular ese concepto de "función social" aplicado específicamente a los bienes del Patrimonio cultural. Sin embargo, y analógicamente a lo que sucede con la regulación legislativa de la propiedad privada y los límites constitucionales que le afectan, ese tipo de regulación legislativa estatal deberá estar orientada únicamente al establecimiento de técnicas y mecanismos de garantía uniformes, que eviten diferentes concepciones "territorializadas" del contenido esencial de una forma específica de propiedad que comprende el conjunto del $\mathrm{PH}$. De este modo, quedarían -entendemos- suficientes ámbitos sustantivos y procedimentales para la actuación de las CCAA, tanto en un plano normativo como ejecutivo, tal y como se puede inferir de la jurisprudencia el TC al interpretar el principio de la función social.

\section{Repercusiones de la jurisprudencia constitucional sobre PH en las potestades normativas de Andalucía}

Con los anteriores presupuestos constitucionales y jurisprudenciales, el Legislador andaluz ha hecho uso de sus atribuciones estatutarias con un criterio no demasiado restrictivo sino, por el contrario, suficiente para responder adecuadamente al compromiso estatutario (artículo 12-3-6) en defensa del patrimonio históricoartístico de la Comunidad ${ }^{11}$. Obviamente el ejercicio de sus potestades normativas no podía desconocer los límites constitucionales marcados por una legislación estatal, contenida en la Ley de PH de 1985, cuya operatividad se asemeja mucho a cualquier otra normativa de naturaleza "materialmente básica".

No obstante, si se centra el punto de mira en las novedades que aporta sobre esta última las disposiciones normativas autonómicas, se observan algunos métodos y técnicas instrumentales que permitirían elevar los standards de protección cultural en el territorio de la Comunidad Autónoma. Este enfoque proporciona por lo demás la medida concreta del alcance con que han sido interpretadas las competencias autonómicas sobre $\mathrm{PH}$, en el juego dialéctico con que actúan dentro de un complejo normativo formado por otros referentes constitucionales (art. 149-1 ${ }^{\circ}$-28) y legislativos (Ley estatal del PH).

Con esta propuesta de análisis el primer diagnóstico debe recaer por lógica en la Ley andaluza de Patrimonio Histórico de 1991, principal normativa con la que se desarrollan los compromisos y competencias estatutarios. Sin ánimo de hacer un examen exhaustivo de los contenidos y características de esta Ley, preferimos centrar nuestra atención en alguna de las innovaciones más relevantes que se introducen en ella respecto de la Ley estatal de PH de 1985. Quizás porque de este modo se obtenga una medida real del alcance de las competencias culturales de Andalucia. Desde esta perspectiva se puede apreciar un esfuerzo del legislador andaluz por complementar y perfeccionar los métodos de protección de los bienes de interés cultural.

En efecto, la Ley 1/1991 innova el sistema de la legislación estatal mediante la creación de otras categorías de bienes culturales sobre las que se proyecta la tutela de la Administración autonómica. En primer lugar, se dispuso la implantación de un método de clasificación alternativo al previsto en la ley estatal de 1985 -el Catálogo General del Patrimonio Histórico de Andalucía- cuyo objetivo se centra tanto en la "salvaguardia" como en la "consulta" y "divulgación". El contenido de ese nuevo inventario deberá englobar todos los "bienes de la cultura" que -así quedan definido en el artículo 1- "se encuentran en Andalucía y revelan un interés artístico, histórico, paleontológico, arqueológico, tecnológico, documental, bibliográfico científico o técnico para la Comunidad Autónoma"12. La duda en este punto reside en determinar si en el sistema de catalogación propiamente andaluz pueden estar comprendidos todos y cada uno de los bienes declarados de interés cultural. Las posibles dudas que se plantean a este respecto encuentran una respuesta satisfactoria en la Disposición Transitoria de la ley andaluza, que prescribe sin ambigüedad alguna la obligación de la Consejería de Cultura de inscribir en aquel Catálogo General "los bienes declarados o en trámite de declaración" ${ }^{13}$. La duda en todo caso se mantiene legalmente en lo que se refiere a los que no hayan sido declarados, sobre los cuales no recaería ninguna obligación legal de inclusión.

Mayor interés presenta la regulación autonómica al implantar efectos de diferentes proporciones como resultado del proceso de catalogación. Con una vocación casi "ejecutiva" de los fines de conservación marcados en la legislación estatal, se contempla una doble gama de consecuencias para los bienes culturales inventariados en el Catálogo andaluz. Cabe una primera fórmula de catalogación a efectos únicamente descriptivos o de simple inscripción general, si bien esto no implica la ausencia total de obligaciones para los propietarios o poseedores de esos bienes, así como la eventual imposición de sanciones para casos de incumplimiento de aquellos deberes legales (art. 8$\left.1^{\circ}\right)$. Pero además, una de las novedades de la ley andaluza consiste en haber configurado una categoría de bienes inventariados a los que se puede aplicar un régimen especifico, que supone una mayor dosis de intervencionismo público en forma de "instrucciones particulares" (art. 8-2 ${ }^{\circ}$. Lo que nos llama poderosamente la atención es esa especie de principio de "prevalencia" implícito, y contenido en una cláusula de la propia norma andaluza, en virtud de la cual se supedita la aplicación del sistema de protección regulado en la ley 1/1991 "en todo cuanto resulte compatible con la legislación del Estado".

Quedaria pendiente de resolver la duda de constitucionalidad que creemos- plantea razonablemente lo previsto en el artículo 15 del Real Decreto 111/1986, de desarrollo parcial de la Ley de PH de 1985. En ese precepto reglamentario se establece indirectamente la competencia del Gobierno central para la declaración como bien de interés cultural, al disponer que ese acto se lleve a cabo mediante Real Decreto. Una atribución que chocaría abiertamente con la interpretación sostenida por el TC en la Sentencia 17/1991, en donde se limita ese 


\section{$070-071$ \\ Debate e Investigación}

El derecho andaluz del PH desde una perspectiva constitucional

\section{PH48 - Abril 2004}

tipo de declaración a los bienes del Patrimonio nacional y adscritos a servicios públicos de la Administración estatal. Sin embargo, el Reglamento de ejecución de la ley estatal de PH introduce un mecanismo que podriamos denominar de "cogestión", contradictorio con la interpretación que ha respaldado la jurisprudencia constitucional sobre la potestad exclusiva -y excluyente- de las CCAA en el procedimiento "declaratorio" de los bienes que poseen un interés cultural.

La dimensión constitucional y estatutaria proporciona seguramente una buena medida -discutible pero sin duda válida- para valorar jurídicamente la regularidad de alguna operación especifica que pretende llevar a cabo el Estado dentro de la Comunidad. Es el caso de la creación, anunciada solamente por ahora, de un Consejo encargado de gestionar la conservación y utilización del conjunto monumental de la Alhambra y el Generalife. Contemplado en un Real Decreto 864/1984, donde se traspasan a Andalucía funciones y servicios de carácter cultural, la cuestión más polémica de su puesta en funcionamiento radica en la más que probable invasión que tendrá lugar de la esfera competencial reservada a la Comunidad Autónoma. Entre los motivos que pueden dar lugar a una impugnación fundada de esta iniciativa estatal destacaríamos la atribución a ese organismo de funciones de carácter ejecutivo o de gestión que deben corresponder en exclusiva a la Administración autonómica. Probablemente, la imposición de un mecanismo de colaboración (Estado-Comunidad Autónoma) supera los márgenes de un genérico deber que se proyecta, como un principio implícito dentro del diseño constitucional del Estado Autonómico, a las relaciones institucionales entre ambas esferas político-administrativas ${ }^{14}$. Sin embargo, el problema -a nuestro juicio- es que la auto-limitación de la competencia estatutaria sobre patrimonio histórico (art. 13-27º "sin perjuicio de lo que disponga..."), obliga a aceptar de nuevo la referencia de lo dispuesto en el artículo 149- $1^{\circ}-28$ como criterio último y definitivo para determinar las competencias ejecutivas de la Comunidad; y con ello igualmente, la con- validación que ha hecho el TC del desarrollo normativo de esa misma competencia contenido en la Ley estatal de PH de 1985. Ahora bien, y precisamente por este motivo, el eventual ejercicio de alguna competencia estatal de naturaleza ejecutiva sólo podria tener lugar cuando la Administración cultural no garantizara la protección ni el cumplimiento de la función social (Art. 4, Ley del PH) de cualquier bien cultural ubicado en su territorio y sobre el que recae con carácter preferente la intervención de una competencia estatutaria.

La doctrina jurisprudencial del TC va a tener seguramente una aplicación significativa en la nueva legislación urbanística de Andalucía. En efecto, la Ley 7/2002, de Ordenación Urbanística de Andalucía declara ya como uno de los principios que deben regir la planificación urbana el respeto y protección del principio rector del artículo 46 de la CE. Desde una perspectiva competencial, en virtud de las atribuciones constitucionales y estatutarias sobre ordenación del territorio y urbanismo, la definición del modelo urbanístico quedaría, por tanto, dentro de los límites de un espacio competencial favorable a la Comunidad ${ }^{15}$. Los límites de lo que comprendería un "doble" título autonómico (urbanismo y patrimonio histórico) quedan bastante diluidos, y en la práctica parecen por lo tanto escasamente, en la reserva estatal de competencias tan genéricas como legislación civil (Art. 149-1 ${ }^{\circ}-8$ ) o la garantía de condiciones básicas para el ejercicio de derechos constitucionales (Art. 149-1 ${ }^{\circ}-1$ ).

En el campo material de la ordenación urbana rigen asimismo los presupuestos señalados por la doctrina del TC a la hora de legitimar la intervención del Estado -incluida la ejecutiva- para garantizar la conservación de los inmuebles (y conjuntos monumentales históricos) frente a la expoliación; es decir, y en el terreno concreto del desarrollo urbanístico, para evitar cualquier actuación contraria a la función social que debe cumplir esos bienes ocasionada presumiblemente por una regulación urbanistica contraria a ese objetivo. Pero

\section{Opinión del lector} Cambios políticos y de mentalidades

\author{
A. Enrique Salvo Rabasco \\ Licenciado en Historia del Arte. Restaurador de Obras de Arte
}

La legislación sobre el patrimonio está directamente relacionada con los contextos histórico-sociales que se desarrollan en los ámbitos culturales. De esta manera, se ven afectados no sólo las instituciones y los bienes culturales, sino también la relación del público con estos bienes, dado que la Administración será la que ponga al servicio del espectador la obra de arte desde una perspectiva u otra.
Cabrian citar muchos ejemplos muy claros en nuestra historia más cercana, pero creo que es el folklore andaluz (en su acepción más rica y cultural) el que más ha salido beneficiado de esta cuestión. Los cambios de perspectiva sobre las Artes Populares han hecho que se pongan en valor muchos caracteres, alejándose radicalmente de instrumentaciones que se produjeran en tiempos anteriores. La lectura absolutamente objetiva (y profesional) con que comienza a tratarse este género de arte es claro ejemplo del cariz que conllevan cambios políticos y de mentalidades.

Entendiéndolo de esta manera, la Gestión Cultural en su propia evolución puede convertirse en un arma de doble filo. La puesta en valor de caracteres muy atractivos pueden suponer reclamos que, como si de una carnaza se tratase, tratan de beneficiarse el voto de los ciudadanos. Lo peor sucede cuando ésta se convierte en medio de presión entre Administraciones bloqueando la Gestión Cultural y evitando que ésta se acerque a 
se trataría en todo caso de una competencia ejecutiva "residual" o "subsidiaria", en defecto o por pasividad de la Administración autonómica, competente como regla general para aprobar esa planificación urbana y el régimen jurídico específico que afecta al patrimonio histórico de naturaleza inmueble. Por otro lado, la competencia autonómica tiene entidad suficiente como para no estar sujeta a condiciones de uniformidad juridica que impidan propuestas regulativas diferenciadas a las que se prevén en la Ley estatal del PH.

${ }^{1}$ Una de las tesis doctrinales más representativa que defienden el carácter normativo de los principios y derechos sociales sería la de GOMES CANOTILHO, J.M. Tomemos en serio los derechos económicos, sociales y culturales. En Revista del Centro de Estudios Constitucionales. SeptiembreDiciembre. 1988. Asimismo CASCAJO CASTRO, J.L. La tutela constitucional de los derechos sociales. En Cuadernos y debates, núm. 5. Centro de Estudios Constitucionales. Madrid. 1988.

${ }^{2}$ Muñoz Machado considera que esta concurrencia total o "paralelismo pleno" que caracteriza especialmente la distribución de competencias en materia de cultura, implica la posibilidad de "admitir el ejercicio del mismo tipo de funciones sobre la misma materia por las instancias centrales y autonómicas". En MUÑOZ MACHADO, S. Derecho Público de las Comunidades Autónomas. Madrid. 1982. Pág. 585.

${ }^{3}$ Tal y como ha declarado con nitidez el Tribunal Constitucional, en relación con esta materia puede intervenirse (por el Estado) no sólo desde la competencia sobre patrimonio histórico sino también desde la cultura. Sin embargo, no cabe -a su juicio- proyectar de manera incontrolada una atribución como la contenida en el artículo $149-2^{\circ}$, en la medida en que no constituye un título que se superponga automáticamente a los demás títulos competenciales más específicos, proyectando su alcance a "ámbitos no queridos por el constituyente, por efecto de aquella incardinación general del patrimonio histórico en el término cultura". Vid. Sentencia (STC) 17/1991.

${ }^{4}$ Sobre una interpretación algo más restrictiva del alcance de la competencia estatal del artículo 149$2^{\circ}$ véase MONTILLA MARTOS, J.A. La constitución del Consejo de la Alhambra a la luz de la Jurisprudencia constitucional. En Revista Andaluza de Administración Pública, nº 34. 1999, pp. 127 y ss.

${ }^{5}$ Sobre la problemática competencial de esta disposición constitucional vid. ESTEVE PARDO, J. En Competencias del Estado y de las Comunidades Autónomas en materia de cultura (Comentario a la reciente jurisprudencia del Tribunal Constitucional). En Revista Catalana de Derecho Público. $n^{\circ} 4$, pp. 101 y ss.

${ }^{6}$ Esta tesis la hemos venido manteniendo en RUIZ-RICO RUIZ,G. El Estado social autonómico: eficacia y alcance de las normas programático-sociales de los Estatutos de Autonomía. En Revista Española de Derecho Constitucional. №. 65, mayo-agosto, 2002.
${ }^{7}$ El concepto de expoliación está definido en el artículo cuarto de la Ley 16/1985: "a los efectos de la presente Ley se entiende por expoliación toda acción u omisión que ponga en peligro de pérdida o destrucción todos o algunos de los valores de los bienes que integran el Patrimonio Histórico Español o perturbe el cumplimiento de su función social". La respuesta que dio el TC fue bastante clara en este punto: Una hipotética invasión competencial no vendría así dada por la utilización en el precepto de legal de la expresión "perturbe el cumplimiento de su función social", sino por una aplicación extensiva en cada caso, y es alli donde cabría remediarla. El precepto no resulta, pues, contrario a la Constitución según el sentido que se indica, y tanto menos cuanto que, en la parte no impugnada, respeta la acción protectora de las Comunidades Autónomas, a las que en primer lugar estimula, para autorizar la actuación de la Administración del Estado sólo en defecto de la de aquéllas.

${ }^{8}$ BARRERO RODRIGUEZ,C. La incidencia de la ley 7/2002, de 17 de Diciembre, de ordenación Urbanistica de Andalucia en el régimen jurídico de sus conjuntos históricos. . Revista Andaluza de Administración Pública, nº 49, 2003, pp78-79.

${ }^{9}$ Nos referimos al artículo 4 de la Ley de PH, que faculta al Estado para "interesar del Departamento competente del Consejo de Gobierno de la Comunidad Autónoma correspondiente la adopción con urgencia de las medidas conducentes para evitar la expoliación", y para el supuesto de ser desatendido ese requerimiento se establece que "la Administración del Estado dispondrá de lo necesario para la recuperación y protección tanto legal como técnica del bien expoliado".

${ }^{10}$ Nos referimos a la Sentencia del TC (STC 195/1998) que resuelve la impugnación de la Comunidad Autónoma de Cantabria contra la Ley estatal 6/1992 por la que se declaraba Espacio natural protegido las Lagunas de Santoña.

${ }^{11}$ Sobre un balance de la legislación aprobada en Andalucia ver BARRERO RODRíGUEZ, C. El derecho andaluz del Patrimonio histórico en el vigésimo aniversario del Estatuto de Autonomía. Revista Andaluza de Administración Pública. $n^{\circ}$ extraordinario 2/2003. Vol. II. Pp. 337-357.

${ }^{12}$ Como se puede apreciar, el legislador andaluz parece haber adoptado un doble criterio delimitador de la competencia autonómica sobre Patrimonio histórico-cultural. De una parte, y como condición preliminar, el de su ubicación en el territorio de la Comunidad (principio de territorialidad). En segundo término, el criterio del "interés" sustantivo (cultural, arqueológico, documental, etc.) de los bienes de la cultura; es decir, su ámbito de aplicación no se limita a proteger aquellos bienes culturales que tengan sólo un " interés autonómico", en cuanto representativos de la "cultura andaluza", sino que por el contrario se extiende a todos los que tengan una relevancia cultural, sea ésta de carácter regional o general.

${ }^{13}$ Vid. BARRERO RODRÍGUEZ, C. En El derecho andaluz del Patrimonio histórico... Cit., p.343.

${ }^{14}$ Vid. MONTILLA MARTOS, J.A. Cit. Pp. 128 y ss.

${ }^{15}$ Vid. BARRERO RODRÍGUEZ, C. La incidencia de la Ley 7/2002, de 17 de Diciembre, de Ordenación Urbanística de Andalucía en el régimen jurídico de sus conjuntos históricos. En Revista Andaluza de Administración Pública., $n^{a} 49,2003$. pp. 75 y ss. los ciudadanos, tal y como está ocurriendo con el Antiguo Edificio de la Aduana de Málaga.

A partir de estos preceptos podemos concluir que la descentralización autonómica, en cuanto que ha contribuido a generar legislaciones que han acercado las realidades patrimoniales de sus conciudadanos a lo que estas significan, ha favorecido la participación ciudadana, porque el público se siente más identificado con lo que le rodea.

No sólo tenemos que sacar conclusiones negativas. Todos estos fenómenos que enumeramos implican que existe una creciente preocupación por el Patrimonio y consciencia de la significación que éste tiene para los ciudadanos. Pilar básico en el estudio del Patrimonio está la representatividad de éste para sus vecinos, a partir del cual se articulan muchos de los preceptos de algunas disciplinas como la Restauración (respeto por la obra de arte).
En conclusión, oteo un futuro esperanzador en los tratamientos patrimoniales de las Administraciones, siempre que no se prostituyan los pilares básicos de la etimología Patrimonial. Además de todo lo expuesto, parece ser que el Arte se ha convertido en válvula de escape para los estereotipados genotipos que dominan nuestra sociedad. No hay que ser apocalipticos y hemos de buscar el sol entre las nubes, y parece que, aunque el mal gusto y los badulaques inunden nuestra vida diaria, siempre quedará un reducto para viajar a mundos ideales o terrenales, a través del oasis que el Arte se ha dado en construir. 